\title{
A figura do imigrante no filme M. Lazhar: uma tradução do mito do estrangeiro
}

Eloá Catarine Pinto Teixeira ${ }^{1}$

Resumo: $\mathrm{O}$ artigo apresenta um breve estudo sobre a representação do imigrante na narrativa fílmica M. Lazhar, dirigida pelo cineasta canadense Philippe Falardeau e lançada no Québec em 2011, às luzes da tradução cultural. Nesse artigo, busca-se analisar a figura do imigrante lida como uma tradução do mito do estrangeiro, que constitui uma figura literária das Américas e também um lugar de memória para a cultura quebequense. $\mathrm{O}$ aporte teórico empregado responde à premente necessidade de se rever o conceito de "identidade quebequense" como sendo o único lugar de representação para o sujeito da nação do Québec, contribuindo, portanto, para uma ampliação do conceito de identidade aplicado às produções artístico-culturais dessa comunidade. Palavras-chave: Identidade quebequense. Mito do estrangeiro. Tradução. Cinema canadense.

\section{The immigrant image in the film called M. Lazhar: a translation of the foreigner myth}

\begin{abstract}
This article presents a brief study on the representation of the immigrant in the filmic narrative M. Lazhar, directed by the Canadian filmmaker Philippe Falardeau, released in Quebec in 2011, under the theoretical basis of cultural translation studies. In this article, the author seeks to analyze the image of the immigrant taken as a translation of the foreigner myth, which constitutes a literary figure of the Americas and also a place of memory for Quebecois culture. Our theoretical choices answer the urgent need to review the concept of "Quebecois identity" as the only place of representation of the Quebecois native, thus contributing to an expansion of the concept of identity applied to artistic and cultural productions of such community.
\end{abstract}

Keywords: Quebecois identity. Myth of the Foreigner. Translation. Canadian movies.

\section{Introdução}

A participação do Outro na formação de uma identidade quebequense tem sido tema de amplos debates na teoria cultural do Québec. Numa nação em que o Outro constitui um dos operadores culturais mais fortes, o debate sobre as noções de migrância, nação e pertença fundam um novo panorama identitário local. Diferença e alteridade

\footnotetext{
${ }^{1}$ Doutoranda inscrita na linha de pesquisa Estudos em Tradução Cultural e Tradução Intersemiótica, do Programa de Pós-Graduação em Literatura e Cultura da Universidade Federal da Bahia (PPGLitCult UFBA). E-mail de contato: e_catarine@hotmail.com. End: Rua Barão de Jeremoabo, no 147 (CEP: 40170115),Campus Universitário Ondina, Salvador-BA.
} 
passam, assim, a serem considerados como operadores discursivos que buscam representar a condição de estrangeiro, imigrante, Outro no espaço quebequense.

Segundo o teórico cultural Pierre Ouellet (apud Janet Paterson, 2007), a noção de “interculturalidade", característica de sociedades pós-coloniais, promove uma "contínua migração do sujeito" para além de si mesmo. Seria um movimento de migração do pensamento, isto é, "um pensamento dinâmico e flexível em que a ênfase é colocada em sua própria relação com o Outro", retirando-o de uma categorização estanque em que esse Outro é transformado em objeto a ser examinado e julgado, dentro de perspectivas redutoras.

No século XIX, época em que a Nouvelle France (território que viria a compor o atual Québec) começa a sentir os efeitos da presença estrangeira em seu ambiente, a presença estadunidense se faz notar mais fortemente em território canadense. Com o desencadear da Segunda Guerra, essa presença se acentua e se torna mais visível através dos meios de comunicação desenvolvidos pelos americanos como estratégia de controle da ação de inimigos ${ }^{2}$.

\section{Refundando o mito}

Conforme a pesquisadora Ana Rosa Neves Ramos (1995), no artigo Para onde vai o Québec?, essa presença se reverteria numa sensação de ameaça por parte da comunidade canadense francesa fundando um novo imaginário para a cultura local. No entanto, a produção artística e cultural da época teria promovido uma "nacionalização do imaginário"

\footnotetext{
${ }^{2}$ Esse tema é mais amplamente discutido em minha dissertação de mestrado intitulada Representações do estrangeiro na adaptação fílmica Le Survenant: processos de alteridade numa perspectiva intersemiótica. 2013. "Com a Segunda Guerra, essa presença seria acentuada, principalmente no que se refere aos meios de comunicação desenvolvidos pelos americanos para interceptar mensagens de grupos inimigos. É quando a produção artística e intelectual canadense francesa funda a ideia de uma "nacionalização do imaginário" no Québec, instaurando assim o debate acerca de uma pretensa cultura quebequense (...)"
} 
do quebequense e assim promovido o debate em torno da existência de uma cultura genuinamente quebequense. Nas palavras da pesquisadora:

“[...] esse objetivo transforma-se rapidamente em nacionalização do imaginário, ou seja: a primeira verdadeira História nacional, um repertório nacional de literatura, o estabelecimento de uma iconografia nacional" (1995, p. 85). Seria, portanto, um momento de (re)fundação de mitos para a memória quebequense. Um desses mitos é o estrangeiro, figura emblemática, que representa uma nova concepção da

identidade quebequense. No espaço das narrativas literárias, podemos citar autores que retrataram os conflitos engendrados pela presença de estrangeiros em território canadensefrancês: temos Germaine Guèvremont com seu romance Le Survenant (1945), que inaugura um estilo anti-terroir de narrativa, abrindo espaço para uma reformulação da concepção de identidade canadense-francesa; desse movimento de reconstrução de uma

"narrativa da nação" através da literatura antiterroir, temos ainda Bonneur d'occasion (1945), da autora Gabrielle Roy, demarcando o início deste período. Conforme a também pesquisadora Bernadete Porto, "na literatura quebequense, o Outro sempre ocupou lugar de destaque, assumindo diversas feições, tais como o mestiço, o louco, o judeu, o estrangeiro etc, entre outros seres das margens" (2007, p.138).

A presença do Outro nas narrativas literárias quebequenses traduz um sintoma da sociedade canadense-francesa, que já há algum tempo se debatia entre a conservação de sua herança colonial francesa e sua crescente abertura às novas influências culturais (escoceses, ingleses, irlandeses, ameríndios etc.), antes deixadas à margem de seu repertório cultural. Dentro desse panorama, já nos anos 1960, com a morte do então Primeiro Ministro do Québec, Maurice Duplessis, observa-se nas produções literárias, acadêmicas e artísticas um movimento de recuperação da memória quebequense, conhecido como Révolution Tranquille.

Esse foi um movimento pacifista que conduziu a uma refundação dessa memória que, em diálogo com sua herança cultural francesa, buscava erguer novos pilares identitários para a sociedade quebequense. Surge então o conceito de identidade quebequense, em contraponto à comunidade canadense-francesa. Assim, ser quebequense 
passou a significar ter uma identidade diversificada, que leva em conta as heranças culturais que antes estavam esquecidas. No entanto, mesmo essa noção de identidade diversificada não pode dar conta da multiplicidade cultural que caracteriza a identidade quebequense hoje, sobretudo no que tange a noção de pertencimento. A questão identitária do Québec está, pois, em vias de ser reordenada.

Conforme o teórico em estudos culturais, Stuart Hall (2006), a identificação é o processo pelo qual o outro constrói a imagem que faz do eu. Um processo contínuo que se estabelece pelo viés da representação. Lemos o outro não necessariamente como ele é, mas como acreditamos que ele nos veja. Assim, ao falarmos em identificação, devemos "vê-la como um processo em andamento".

Neste sentido, a identidade não pode ser percebida como uma instância firmada e unívoca, mas como algo que surge não da identidade já presente no interior dos indivíduos, mas de "uma falta de inteireza que é 'preenchida' a partir de nosso exterior, pelas formas através das quais nós imaginamos ser vistos por outros [grifos do autor]" (HALL, 2006, p. 39). Desse processo resulta a noção de que a identidade é construída pela relação com a parcela que não está presente no eu, isto é, na relação com o Outro, proveniente de diversos lugares, portanto, estrangeiro ao indivíduo. A identidade quebequense, nessa abordagem, seria resultado dessa relação com o estrangeiro. No Québec, sobretudo nos dias de hoje, podemos afirmar que essa relação encontra espaço nos movimentos migratórios. Sobre esse aspecto a pesquisadora em estudos canadenses Zilá Bernd afirma:

Migrações, exílios, diásporas, mestiçagens levam ao questionamento sistemático da pertença única, abrindo uma fenda no debate identitário que precisa ser libertado de seu pacto exclusivo com a língua e com a nação. (BERND, 2010, p. 14)

No entanto, é somente na literatura moderna quebequense que poderemos verificar uma superação dessa noção de identidade unificada para o quebequense, antes percebido como pertencente à cultura canadense-francesa. Neste panorama, Sergio Kokis com seus romances Le pavillon des miroirs (1994) e Errances (1996), dentre outras publicações, ilustra uma nova concepção identitária do sujeito quebequense atual. 


\subsection{Crise no conceito de identidade nacional - análise sobre o filme $M$.}

\section{Lazhar}

Conforme Zilá Bernd (2010), a crise do conceito de identidade nacional homogêneo inicia-se a partir do momento em que as minorias (em relação à posição que ocupam no seio de determinadas sociedades) passam a ocupar os espaços que lhe são devidos, assumindo seus lugares de fala (seu locus enunciativo) e reivindicando identidades específicas, tais como: as mulheres, os negros, os gays, os estrangeiros, os imigrantes etc. Para Bernd (ibid.), essa fragmentação do sujeito abre o debate sobre os conceitos homogêneos de identidade e de literatura nacionais.

É visível, portanto, o interesse da literatura quebequense em retratar as facetas do que ficou conhecido como "mito do estrangeiro". De acordo com o Dicionário de Mitos e Figuras Literárias das Américas - doravante DFMLA - organizado por Zilá Bernd (2007),, em Le pavillon des miroirs o narrador-personagem retratado por Sergio Kokis "sente-se um estrangeiro em seu próprio meio", encontrando no exílio e na alteridade espaçotemporal entre o passado do país de origem, o passado ficcional reinventado pela memória e o presente da enunciação, uma espécie de refúgio para sua narrativa e para uma recomposição de sua identidade multifacetada:

Tanto Le pavillon des miroirs quanto Errances põe em cena a questão da escrita do exílio, mas, sobretudo, chamam a atenção para aquilo que, na e pela escrita, participa da perda, dos desvios de língua e de identidade. (BERND, 2007. p. 268).

Ainda de acordo com o DFMLA, o estrangeiro surge como representação do "outro". Torna-se um veículo de transculturação, presente também na literatura contemporânea latino-americana, e somente percebido como tal a partir da desconstrução do conceito de nação e fronteira geográfica em termos culturais. Nesse sentido, o estrangeiro está presente nas representações que emergem desse processo de transculturação.

Para Jacques Beauchemin (2003), estudioso das questões identitárias no Québec, o Québec se encontraria em um "cruzamento dos caminhos da identidade". Não tendo liquidado a memória canadense-francesa, ao mesmo tempo, ele não se reconheceria inteiramente nela. (p. 37). 
Assim, nos questionamos sobre que imagens o mito do estrangeiro poderá assumir nas diversas produções artísticas e culturais quebequenses. Inferimos, pois, que o imigrante seja talvez a representação mais emblemática do processo de transculturação suscitado pelo mito do estrangeiro no Québec contemporâneo. Propomos, portanto, uma breve análise dessa representação no filme quebequense $M$.

Lazhar, lançado em 2011, no Québec, e dirigido pelo cineasta canadense Philippe Falardeau.

O filme retrata a realidade de um professor argelino que luta para se manter como imigrante no Québec. Com o suicídio de uma das professoras da escola, alunos e demais profissionais são obrigados a conviver com o luto. M. Lazhar vai até a escola oferecer-se como professor substituto de literatura e logo em seguida é contratado.

No entanto, o professor não está atualizado com o sistema de ensino quebequense e vê-se numa encruzilhada entre a necessidade de estar empregado e manter-se no Québec e os dramas vividos pelos alunos, que não hesitam em estabelecer comparações entre o professor substituto e a antiga professora.

Bachir Lazhar (o professor) enfrenta dificuldade em adaptar-se ao novo regime educacional, em que alunos de diversas origens são inseridos em classes normais. A personagem assume uma turma de $6^{\text {a }}$ série que, obrigada a conviver com o trauma causado pela morte da professora, lida com os conflitos engendrados pela metodologia do novo professor.

O suicídio da antiga professora perturba uma aluna em especial, Alice. A aluna tenta lidar com a ausência da professora de maneira mais introspectiva, ao passo que seu colega Simon tenta mostrar outra face do luto - a lembrança. M. Lazhar é levado a perceber que seu papel vai além da transmissão de conhecimentos sobre literatura. O professor deverá ajudar esses alunos a lidar com o trauma provocado pela perda da professora que ele substituiu. 
Num primeiro momento, a turma é representada no filme como um espaço de convívio entre as diversas culturas - uma característica do Québec de hoje em que o fluxo de imigrantes é considerável. Essa representação aparece nos nomes dos alunos que são citados pelo professor no momento da chamada. No momento em que seus nomes são revelados fica evidente que esses alunos provêm de origens diversas.

Questionamentos acerca do nome partem da tradução que o professor dá de seu próprio nome. Ele explica que Bachir Lazhar significa porteur de bonnes nouvelles (portador de boas notícias). Esse é um índice de que Bachir, na qualidade de estrangeiro, conhece as regras sociais que regem o contato com o Outro. Ao colocar seu nome no quadro negro, Bachir estaria simbolicamente reclamando o direito à hospitalidade, de que Derrida fala: “esse estrangeiro, então, é alguém que, para que seja recebido, começa-se por querer saber o seu nome". (DERRIDA, 2003, p. 25).

A questão do nome é crucial neste contexto, visto que será a partir do nome que o estrangeiro será identificado em seu novo ambiente. Entretanto, na concepção derridariana, essa hospitalidade que o estrangeiro demanda da comunidade que o acolhe pode se dar "antes que ele [o estrangeiro] se identifique, antes mesmo que ele seja sujeito, sujeito de direito e sujeito nominável por seu nome de família" (ibid, 2003, p. 27). É o que ocorre na interação do professor com a turma da $6^{\mathrm{a}}$ série. Bachir curiosamente analisa o nome de cada um dos alunos, como quem deseja conhecer a identidade, ou a origem, de cada um deles.

Entretanto, nas relações com seus colegas e especialmente com a diretora da escola, Bachir, logo em seu primeiro contato com a diretora, recusa ser chamado pelo nome (Bachir), preferindo ser chamado por seu sobrenome (Lazhar). Esse é um traço da cultura francesa, em que profissionais e superiores tratam-se com certa formalidade acrescentando ao sobrenome os pronomes Monsieur (Senhor) e Madame (Senhora). Mas, na narrativa fílmica, esse traço perde força e, no decorrer das cenas, é possível observar que essa formalidade não se aplica à cultura quebequense, sugerindo que no trato com o outro, há certa informalidade, comparável à relação entre amigos. 
O tratamento dado ao professor pelo nome é um índice de que ele está sendo aceito na comunidade escolar. Isso fica evidente aos $38^{\prime} 45^{\prime}$ ' do filme, na cena em que os alunos da $6^{a}$ série posam para a foto do anuário da escola. Bachir se exclui da foto, mas é chamado por Alice a incluir-se: Bachir venez dans la photo! (Bachir venha na foto!). O professor se recusa, mas, após a insistência do fotógrafo, ele aceita.

Assim, o nome do professor revela não só sua origem argelina, como também sua condição de estrangeiro, de Outro. Porém, um estrangeiro aceito e ao qual foi concedido o direito à hospitalidade. Conforme Derrida é a referência à origem, dada a partir do nome, que torna possível essa relação de hospitalidade para com o estrangeiro.

Em outras palavras:

Esse direito à hospitalidade oferecido a um estrangeiro 'em família', representado e protegido por seu nome de família, é ao mesmo tempo o que torna possível a hospitalidade ou a relação de hospitalidade com o estrangeiro (...) Nessas condições, não se oferece hospitalidade ao que chega anônimo e a qualquer um que não tenha nome próprio, nem patronímico, nem família, nem estatuto social, alguém que logo seria tratado não como um estrangeiro, mas como um bárbaro. (DERRIDA, 2003, p. 23)

Ao final da chamada, o professor pergunta a uma aluna (Marie Frédérique GarantMacarti) - uma alusão à mistura canadense-britânico-francesa, marcada inclusive por seu sotaque anglófono - sobre que nome ela daria ao filho caso ela casasse com outro aluno

Victor Garrido Larivière, taxado de "retardado mental" por estar repetindo a $6^{\mathrm{a}}$ série aos seus 13 anos de idade. A aluna rejeita veemente essa relação dizendo: J'aurais jamais d'enfants avec lui. ("Eu nunca teria filhos com ele", tradução nossa).

Essa cena traduz a rejeição ao Outro, que aqui aparece sob o estigma de "retardado mental", podendo ainda ser traduzido nos signos de louco, ou de anormal, na linguagem popular. A fala da aluna Marie Frédérique, por sua vez, traduz um sentimento nacionalista involuntário de pertencimento que subjaz à rejeição ao colega. Segundo Kristeva (1994), esse nacionalismo, tendo saído da revolução burguesa, tornara-se o sintoma, primeiramente romântico, em seguida totalitário, dos séculos XIX e XX. Entendemos, 
contudo, que essa seria também uma representação identitária no Québec do século XXI, ano em que se passa a narrativa fílmica em estudo.

A aluna rejeita sua união com um colega de outra origem, porém pertencente ao mesmo território, o Québec. Isso suscita o debate sobre o diálogo intercultural, a possibilidade de convivência entre as diferentes origens culturais sem que necessariamente elas se encontrem unidas numa pertença. Nesse sentido, a recusa da aluna sinaliza uma reação ao processo de alteridade que a união matrimonial imprime nas identidades dos sujeitos envolvidos, o que torna a reação contraditória já que a aluna encontra-se na idade em que o processo de alteridade é latente e é intensificado com o luto.

A identidade aqui aparece como marca de uma pertença ideológica - Marie Frédérique como canadense-francesa e Victor como filho de imigrante. Essa pertença está traduzida na relação entre os traços físicos da aluna (pele clara, traços finos tipicamente europeus, tipo magro, cabelos longos escuros e olhos claros) e seu nome (Marie Frédérique Garant-Macarti). Ao passo que seu colega, Victor Garrido Larivière, revela sua origem chilena através do nome (Garrido), mas possui traços próximos aos de Marie. Vemos então que a identidade pode ser também questionada a partir do corpo.

Sobre esse processo, Paul Gilroy (2008) nos leva a considerar:

por exemplo, como se compõem os laços emocionais e afetivos que formam a base específica da similitude raciológica e étnica, e como estes se tornaram atividades sociais padronizadas e dotadas de traços culturais elaborados. De que maneira esses laços são capazes de induzir atos conspícuos de altruísmo, violência e coragem? (p.127)

Para o teórico em estudos culturais, a identidade termina sendo "uma questão de poder e autoridade" em que um grupo buscaria representar a si numa forma política. Esse grupo poderia ser "uma nação, um Estado, um movimento, uma classe, ou alguma combinação instável de todos eles" (ibid, p.125). No filme, essa busca pela representação de si não se dá pela rejeição da aluna ao colega, mas sim pela dificuldade de M. Lazhar em compreender seu papel diante de uma turma miscigenada de estudantes da $6^{\mathrm{a}}$ série, que 
passam por um processo de luto ao mesmo tempo em que buscam naturalmente formar sua própria identidade.

Essa dificuldade aparece nos 47' do filme, na cena em que, numa reunião pedagógica, o professor conversa com os pais de Marie Frédérique sobre seu comportamento "rígido" e "autoritário" em relação aos colegas. Nesse momento, o professor é levado a refletir sobre si mesmo quando colocado no lugar de estrangeiro pelo pai da aluna, que diz: Vous aussi... toute évidence c'est difficile... vous êtes pas d'ici et forcément il y a des nuances qui vous échappe. Après ça, c'est sur qu'on préfère que vous contantiez d'enseigner et non pas d'éduquer notre fille ${ }^{3}$.

No filme, várias serão as alusões ao professor Bachir Lazhar como sendo um estrangeiro: o professor reage com estranheza ou usa sua língua materna (o árabe), quando os alunos falam em inglês; é rígido quanto a sua prática pedagógica; é taxado de estrangeiro pelos pais de Marie Frédérique; encontra grande dificuldade em adaptar-se ao ambiente informal que a escola apresenta, mostrando-se surpreso com a leveza com que a diretora e seus colegas professores conduzem os alunos, etc.

Todos esses índices corroboram com o entendimento de que o professor Bachir experimenta uma identidade difusa no país estrangeiro, obrigando-se a transitar entre suas crenças entorno da educação dos alunos e o novo regime escolar que se impõe, mais lúdico, menos formal, porém com o agravante de que a escola e, principalmente, a turma da $6^{\mathbf{a}}$ série, tentam superar um trauma. Essa identidade difusa é colocada em questão também aos 33'41', cena em que o professor aparece num tribunal. É quando tomamos consciência da sua real condição de imigrante e de Outro para a comunidade local.

A comunidade está representada na Corte, que figura como símbolo da ordem e da justiça quebequense. Bachir é interrogado pelo promotor e pela juíza quanto ao seu pedido

\footnotetext{
${ }^{3}$ [Para]O senhor também... evidentemente é difícil. O senhor não é daqui e com certeza há nuances que lhe escapam. Depois, é óbvio que a gente prefere que o senhor se contente em ensinar e não em educar nossa filha.
} 
de asilo político para sua família. Bachir teve seu visto aceito e conseguiu migrar da Argélia para o Québec.

No entanto, sua esposa teve seu visto negado e teve que permanecer em seu país, numa condição grave. A esposa de Bachir era professora e havia publicado um livro em que criticava a política argelina. Não é difícil perceber que esse é um fator complicador para as relações de gênero em países cuja representação política é machista. Sobre esse aspecto da narrativa, Gilroy oferece uma reflexão bastante pertinente. Segundo ele, "as diferenças de gênero se tornam extremamente importantes na atividade de construção da nação por serem um sinal de uma hierarquia natural irresistível que está no centro da vida cívica" (GILROY, 2008, p. 156).

Já no início do século XX, o Québec foi palco de um forte movimento feminista, especialmente no que se refere às reformas sociais que beneficiaram as mulheres após a Revolução Tranquila. Esse é um fator que caracteriza sua atual situação política, a de um país em que a participação feminina na política é singular. A pesquisadora canadense Chantal Maillé (2003) afirma que os grupos feministas ocupam um espaço político importante e único na sociedade quebequense. Segundo a pesquisadora, o movimento das mulheres no Québec é "um movimento plural" que luta em favor da diversidade das mulheres, constituindo assim "um lugar importante de ativismo político, exercido no exterior de instituições tradicionais”. (MAILLÉ, 2003, p. 350).

Essa particularidade da questão feminista no Québec segue na contra-corrente do caráter machista da política argelina, em que a mulher sofre fortes coerções. A esposa de Bachir se torna, nesse aspecto, uma representação do Outro, para o sujeito político da nação argelina, de cunho machista. A mulher estaria, nesse sentido, na condição de Outro, subalternizada pelo homem, que estaria no cerne da cultura argelina. Esse entendimento é ampliado quando, na mesma cena, a morte da família de Bachir é revelada.

Tendo o visto negado e correndo perigo de vida, diante das constantes ameaças de morte, a esposa de Bachir tentou deixar ilegalmente a Argélia. Bachir é questionado sobre esse fato e explica à Corte que teria entrado no Québec antes para poder preparar a chegada de sua família, foi isso que o levou a procurar emprego como professor de literatura, 
profissão que na verdade era de sua esposa. A tentativa de fuga da família de Bachir foi descoberta antes que seu visto fosse aceito no Québec. Sua família foi, então, assassinada com um incêndio criminoso em sua residência, na Argélia. Bachir aparece então como um imigrante em luto, o argelino desterrado e desfamiliarizado. Esse índice pode ser visto como uma tradução do que Todorov considera ser o processo de desculturação, conforme o próprio autor explica: “Ce qu'il faut craindre et déplorer, c'est la déculturation elle-

même, dégradation de la culture d'origine; mais ele peut être compensée para l'acculturation, acquisition progressive d'une nouvelle culture, dont tous les êtres humains sont capables ${ }^{4 \prime}$. (1996, p. 23).

Bachir Lazhar vive um processo intenso de "desculturação" pela via da violência. Sua identidade é obrigada a reformular-se e converter-se em estrangeira até mesmo ao seu país de origem, onde ele já não pode retornar e cujo laço se rompe junto com a morte de seus familiares. Perdendo o elo que mantinha com seu país (a Argélia), Bachir é obrigado a reinventar-se e a forjar uma nova identidade. Um processo de alteridade inicia-se então nesse estrangeiro, que agora é apenas mais um imigrante exilado no Québec. Ele vive, pois, nessa "fratura incurável" entre si mesmo e a nação de origem.

Para Edward Said (2003) o exílio seria originariamente um "estado de ser descontínuo" que se opõe ao sentimento nacionalista de pertença a um lugar, a um povo ou a uma herança cultural.

O exílio configura, nesse âmbito, o ponto de ancoragem para uma reconstrução da identidade de Bachir. Seu novo estatuto de imigrado é o ponto de partida para a alteridade na personagem. Segundo Julia Kristeva (1994), teórica das relações entre psicanálise e semiologia, “o estrangeiro é um esfolado sob a carapaça de ativista ou de incansável "trabalhador imigrado". (1994, p. 14). E é assumindo a identidade de "trabalhador imigrado" que o professor iniciará seu processo de aculturação no Québec.

\footnotetext{
4 “O que se deve temer e deplorar é a desculturação em si, degradação da cultura de origem, mas ela pode ser compensada pela aculturação, aquisição progressiva de uma nova cultura, de que todos os seres humanos são capazes”. (TODOROV, 1996, p. 23).
} 
Essa condição de vítima da violência argelina é o que leva Bachir a aproximar-se dos alunos da $6^{\mathrm{a}}$ série, de modo que o imigrante passa a melhor compreender o sentimento de perda de seus alunos. Propondo-se a ajudá-los a superar seu próprio trauma, Bachir inicia pequenas mudanças em sua metodologia, inserindo os carimbos coloridos que sua esposa utilizava, na correção das atividades dos alunos. Além disso, o professor passa a ler obras de autores consagrados no Québec, mas que guardam certa familiaridade com sua condição de imigrante e agora, exilado pelo luto e pela impossibilidade de retornar ao seu país. Não é em vão, portanto, que o professor aparece lendo, por exemplo, L'énigme $d u$ retour (O enigma do retorno, tradução nossa), romance escrito por Dany Laferrière, escritor, roteirista e jornalista consagrado no Québec (e eleito pela Academia Francesa), de origem haitiana, negro e que também teve que exilar-se no Québec no final dos anos 1970 .

Essa cena traduz o processo de alteridade iniciado com o luto e em situação de exílio, que leva Bachir a buscar identificações com sua nova nação, o Québec. A comunidade quebequense é representada como sendo uma nação de exilados, por assim dizer, em que os estrangeiros - nesse caso, os imigrantes - encontram asilo, aceitação e convivialidade. Enfim, o Québec seria esse local de refúgio para os perseguidos, marginalizados e incompreendidos em sua terra natal. Porém, nessa nova comunidade, Bachir é um estrangeiro cujos direitos são limitados pela ordem local.

\section{Conclusão}

Nesse âmbito, Jacques Beauchemin (2008) nos orienta a refletir sobre o fato de que essa "apologia do pluralismo e da diferença", que caracteriza a política de imigração do Québec, é “efetivamente, ambígua quanto ao lugar que ela concede à comunidade de história através da promoção da diversidade e do reconhecimento dos direitos de alcance identitário" (ibid, 2008, p. 30). Essa ambiguidade está na proposta de valorização da presença do Outro para a construção de uma identidade quebequense que, ao mesmo tempo, nega ou limita o direito à pertença, à nacionalidade para esse Outro. O resultado desse processo seria, portanto uma contingência: 
A contingência na questão do Québec está na contradição de uma afirmação cidadã totalizante num espaço em que se proclama uma necessidade de reconhecimento das solicitações dos diversos agrupamentos da sociedade civil. (BEAUCHEMIN, J., 2008, p. 28).

Desse ponto de vista, podemos concluir que será na zona denominada "contingência" que os mecanismos de subjetivação serão processados e colocados como discursos de identidade. Ela constitui, portanto, um lugar de retomada e de reformulação de ideologias, crenças, mitos que, não respondendo mais às demandas identitárias atuais, deverão ser relidos e ressignificados na atualidade. Deste modo, as narrativas (quer literárias, quer fílmicas) deveriam ser lidas como discursos de representação, servindo, portanto, como um contra discurso que rejeita a pertença como sendo o lugar único da identidade.

A tradução cultural, nesse âmbito, contempla um debate que ultrapassa os limites discursivos. Ela insere as narrativas num processo dialógico multidisciplinar, permitindo que os textos sejam enriquecidos pelos diversos olhares lançados sobre eles. A tradução, por fim, cumpre um papel relevante na análise das narrativas (sejam elas literárias ou não), ampliando assim seu próprio campo de atuação.

\section{Referências}

BEAUCHEMIN, Jacques. O que é ser quebequense: entre a preservação de si e a abertura ao outro. In: GAGNON, Alain-G. (org.). Quebec: estado e sociedade. Trad. Zilá Bernd (org.). Porto Alegre: UFRGS Editora, 2003.

BERND, Zilá (org.). Dicionário de figuras e mitos literários das Américas (DFMLA). Porto Alegre: UFRGS Editora, 2007.

BERND, Zilá (org.). Imaginários coletivos e mobilidades (trans)culturais. Porto Alegre: Nova Prova, 2008.

BERND, Zilá (org.). Colocando em xeque o conceito de literatura nacional. In: CARRIZO, Silvina L.; NORONHA, Jovita Maria G. (org.). Relações literárias interamericanas: territórios e cultura. Juiz de Fora: EDUFJF, 2010. p. 13-21.

DERRIDA, J.; DUFOURMANTELLE, Anne. Anne Dufourmantelle convida Jacques Derrida a falar da hospitalidade. Trad. Antonio Romane. São Paulo: Editora Escuta, 2003.

GILROY, Paul. Identidade, pertencimento e a crítica da similitude pura. In: Entre campos: Nações, culturas e o fascínio da raça. São Paulo: Annablume, 2008. 
HALL, Stuart. Quem precisa da identidade? In: SILVA, Tomaz Tadeu da. Identidade e diferença (org.): a perspectiva dos estudos culturais. Petrópolis: Vozes, 2011. p.103133. HALL, Stuart. A identidade cultural na pós modernidade. 10 ed. Rio de Janeiro: DP\&A Editora, 2010.

KRISTEVA, Julia. Estrangeiros para nós mesmos. Trad. Maria Carlota Carvalho Gomes. Rio de Janeiro: Rocco, 1994.

MAILLÉ, Chantal. O movimento das mulheres no Québec: história e atualidade. In: GAGNON, Alain-G. (org.). Quebec: estado e sociedade. Trad. Zilá Bernd (org.). Porto Alegre: UFRGS Editora, 2003.

RAMOS, Ana Rosa. Para onde vai o Québec? In: LAVALLÉE, Denise Maria Gurgel (org.). Anais do III Congresso Internacional da Associação Brasileira de Estudos Canadenses (ABECAN): Laços de cooperação cultural Brasil-Canadá. Salvador: Gráfica da UNEB, 1995.

SAID, Edward. Reflexões sobre o exílio. In: Reflexões sobre o exílio e outros ensaios. Trad. Pedro Maia Soares. São Paulo: Companhia das Letras, 2003.

Recebido em 15 de setembro de 2014 Aceito para publicação em 17 de dezembro de 2014 